\section{A N A D DRESS}

ON

\section{THE PRESENT STATE OF ANATOMICAL SCIENCE.}

\section{Delivered to the Anatomical and Physiological Department of the Biological Section of the British Association: Bristol, August 25th, 1875.}

BY JOHN CLELAND, M.D., F.R.S.,

Piofessor of Anatomy and Physiology in the University of Galway; Vice-President of the Section.

I SHALL not venture to occupy the time of the Section with any risum! of the work done in anatomy and physiology during the past year, as such information is readily accessible in the pages of journals and yearbooks. I shall content myself with making some comments on the condition of anatomy at the present time in a few important particulars.

I had intended to speak also of some subjects connected with physiology; but I find that I cannot do so without lengthening my remarks to a greater extent than might be desirable. I shall be content, therefore, so far as that science is concerned, to mention that, although experimental physiology is probably less cultivated in this country than in any other in which biology is studied, it has been practically decided by Parliament that it is quite time to put some check on investigation in that direction; for, as every one knows, a Royal Commission has been appointed to inquire into vivisection. In the scientific world, all are agreed, whatever opinions may prevail in other sections of the community, that the man who would wantonly inflict pain on a brute beast is himself a brute, and deserving to be roughly handled; and because there is no difference of opinion on that subject, and because no experimental science can well prosper if one man is to judge for another what experiments are justifiable to institute or to repeat, or are likely to give important results, I do deplore the clamour which well-meaning persons have raised, and regret that it has been so far yielded to.

In anatomy, the most important progress in recent years has been made in those departments which abut most closely on physiology; namely, the microscopy of the tissues and development. The whole conception of the nutrition of the body has become altered in comparatively recent years by the additions to our knowledge of the nucleated corpuscles, which are the living elements of which it is composed; and principally by the recognition of the secondary nature of cell-walls, the close connection or even continuity of the nerves with other textures, and the identity of the white corpuscles of the blood with amoboid or undifferentiated corpuscles outside the vessels. The origin of every living corpuscle from corpuscles pre-existing is no longer difficult to imagine, but may, I incline to think, be almost looked on as proved. The history of each may be traced back through conjugated germs to the corpuscles of preceding generations in uninterrupted succession, and the pedigree of the structural elements is seen to differ in no way from that of individual plants or aninials. It is true, indeed, that no absolute proof exists that new living corpuscles originating by mere deposit are not added to the others; but the evidence against such a thing taking place is exactly of the same description as that which exists against spontaneous generation of independent organisms; viz., that things previously unexplained by the theory of parentage are explained now, while, on the other hand, there is no sufficient evidence of the origin of life by any other mode.

The advance of histolozy in recent years is owing in part to the facility of obtaining good microscopes at moderate prices having brought the study within the reach of a great and increasing crowd of observers. At first, the progress of histolosy was influenced by the the steps of improvement in the manufacture of microscopes; but now, for a number of years back, we have been in possession of instruments thoroughly suited for the investigation of tissues; and I think it will be generally admitted that the highest powers which have been manufactured are not those which have advanced discovery most, or are most likely, in the present state of science, to yield the richest harvest. We appear to be more dependent now on new methods of preparation. Thus, if we go back for a considerable number of years, we cannot but remember what a valuable addition glycerine proved when it came first into use, and what a harvest of discovery followed the introduction of chromic acid. More recently, the methods of transparent injection, of preparing sections by imbedding, the freezing of tissues, the use of carmine and other pigments for staining, the resort to metallic depositions by the use of osmic acid, silver and gold, and a variety of other additions to our means of preparation have productel results of an astonishing kind, which have changed the whole aspect of histology from that which it wore when I myself first took an intercst in the subject.

Leaving histology, I shall devote the rest of my remarks to the morphology of the vertebrata. Here I am less disposed to indulge a g atulatory vein. No doubt, within the last dozen years, we have had work to be grateful for. Worthy of a prominent place in this, as in other departments of anatomy, is the encyclopxdic work, the Leçons, of Milne-Edwards, invaluable as a treasury of reference to all future observers; while the memoirs of Gegenbaur on the carpus, on the shoulder-girdle, and on the skulls of Selachian fishes, and Kitchen Parker's memoirs devoted to mature forms, may be taken as examples that morphological problems suggested by adult comparative anatomy have not lost their attraction to men capable of elaborate original research. And I the more willingly select the names of these two writers, because, on one subject on which they have written, the shoulder-girdle, I am compelled to differ from their conclusions, and to adhere rather to those of Owen, so far as the determination of the ditferent elements in fishes is concerned; and by stating this (although the subject cannot be now discussed) I am enabled to illustrate that the appreciation of the value of elaborate and painstaking work is $a \cdot m a t t e r$ totally distinct from agreement with the conclusions which $m i y$ be arrived at in the investigation of complicated problems, although wisdom and penetration as to these must ever command admiration.

But, when one looks back on the times of Meckel and Cuvicr, and on the activity inspired by the speculations of the much abused Oken, the writings of Geoffroy St. Hilaire, the less abstrusely speculative part of the works of G. C. Carus, and the careful monographs of many minor writers; when one reflects on the splendicl grasp of Johannes Muiller, and thinks of the healthy enthusiasm created in this country for a number of years by Owen's Archetype and Homoligies of th' I $^{\prime} \%$. tebrate Skeleton, and then contemplates the state of vertebrate morphology at the present moment, it seems to me that its homolo rical problems and questions of theoretical interest do not attract so much attention as they did, or as they deserve.

There can be no doubt that a great and curious influence has been exercised on morphology by the rise of the cloctrine of the ori rin of species by natural selection. Attention has been thereby directcd strongly for a number of years to varieties; and probably it is to this doctrine that we owe the larger number of observations made on varations of muscles, nerves, and other structures. Particularly elaborate have been the records of muscular variations, very praiseworthy, in teresting to the recorders, very dry to most other people, and hitherto, so far as I know, barren enough of any general conclusions. So wuch the more credit is due to those who have worked steadily in faith that beauty will emerge to grild their results some day.

But the doctrine of natural selection has had a further effect in anatomical study, aiding the reaction against the search for internal laws or plans regulating the evolution of structures, and directing attention to the modifying influences of external agencies. This effect has happened naturally enough, but it has been far from just; rather is it a penclulum-like swing to another extreme from what had previously been indulged in. The doctrine of natural selection starts with the recognition of an internal formative force which is hereditary; and in the development of the doctrine, the limits of hereditary resemblance have been greatly studied; and further, it will be observed that one of the fundamentals of the doctrine is, that the formative force alters its character gradually and permanently when traced from generation 10 generation in great tracts of time. Now I am not going to enter $0: 1$ a threadbare discussion of the origin of species in this company: sufice it to say that, while the existence and extensive operation of stch it thing as natural selection seems to have been convincingly prove?, it is a very different thing to allege that it has been the sole, or even the principal agent in producing the evolutions of living forms on the frat of the earth. So far as anatomy is concerned, it is a secondary mitict whether the link between the members of the evolving hosts of life have been genetic or not. But I wish to point out that, even funhag the Darwinian theory to the utmost possible extreme, the action of external agents infers the existence of something acted on; and the ?ess directly they act, the more importance must be given to the hereditary or internal element. We are, therefore, presented with a formative force, which exhibited itself in very simple trains of phenomena in the first beginnings of life, and now is manifested in governing the complex growth of the highest forms. We are set face to face with that form ative force, and are obliged to admit its inherent capability of changing its action; and that being the case, it is more of an assump. 
tion to declare that the changes are all accidental and made permanent by accident of external circumstance, or to consider that it has been the law proper to this force to have been adequate to raise forms, however liable to modification by external circumstances - to raise them, I say, from the simple to the complex, acting through generations on the face of the earth, precisely as it acts in the evolution of a single egg into an adult individual? This is that formative force which has been elaborately shown by Mr. Darwin, in launching his theory of "pangenesis", not only to be conveyed through whole organisms and their seed, but to pervade at all times the minutest particles of each; and merely direct attention to the fact that its extension over the whole history of life on the globe must be granted, and ask if, in the range of forms which furnish at the present day an imperfect key to the ages which are past, there is not exhibited a development comparable, in its progression to definite goals, with what is shown in the life of a single plant or animal. For my own part, I am fully convinced of an unity of plan running through animal forms, and reaching, so far as the main line is concerned, its completion in the human body. I confess that I think that there is evidence that animal life has reached its preordained climax in humanity; and I cannot think it likely that, as myriads of years roll on, descendants differing in toto from man will be developed. To argue the subject would be to enter on the largest subjects of morphological anatomy, and on speculations on which agreement could not be expected. Even, however, in the nature of the variations in the human race there seems to be some evidence that the progress of crolution is to be traced from man, not to other animal forms yet to appear, but, through his psychical nature, into the land of the unseen. Those variations, keeping out of view differences of bulk and stature, which appear to have some relation to geographical position, are principally to be found in the head, the part of the body most closely connected with the development and expression of the mental character; and I may mention that when, some years ago, my attention was directed to the variations of the skull, the only part whose variations in different races I have had opportunity of studying with any degree of minuteness, I became satisfied that in uncivilised races there might be (istinguished skulls which had undergone hereditary degeneration, others which had reached the most advanced development possible for them; and a third set, notably the Kaffirs, with large capabilities for improvement in the future. Indeed, it is beyond doubt, that there is a limit for each type of humanity beyond which it cannot pass in the improvement of the physical organisation necessary for mental action. ${ }^{*}$

There are also some curious indications in human structure of the formative force nearing the end of its journey. In the details of the slieletons of other animals, one sees the greatest precision of form; but there are various exceptions to this neatness of finish in the skeleton of man, and they are found in parts specially modified in connection with the peculiarities of his development, and not requiring exactness of shape for physiological purposes; while, on the other hand, physiognomical mould and nicety of various physiological adaptations are found in perfection. Look at the variations in the breast-bone, especially at its lower extremity, which is never shapely, as it is in the lower animals. Look at the coccygeal vertebræ; they are the most irregular structures imaginable. Even in the sacrum and in the rest of the column the amount of variation finds no parallel in other animals. In the skull, except in some of the lowest forms of humanity, the dorszm sellee is a rasged, warty, deformed, and irregular structure, and it never exhibits the elegance and finish seen in other animals. The curvature of the skull and shortening of its base, which have gradually increased in the ascending series of forms, have reached a degree which cannot be exceeded; and the nasal cavity is so elongated vertically, that in the higher races nature seems scarcely able to bridge the gap from the cribriform plate to the palate, and produces such a set of unsymmetrical and rugged performances as is quite peculiar to man; and to the human anatomist many other examples of similar phenomena will occur.

Questions of homology are matters which must be ever present in the study of structure as distinct from function-both the correspondence of parts in one species to those in others, and the relations of one part to another in the same animal; and perhaps I shall best direct attention to the changes of opinion on morphological subjects in this

* I allude to the circumstances, that, under the influence of civilisation, the length of the base of the skull does not increase, but positively decreases; that the proportion of the extent of the arch to the base has strict limits; that the curvature of the base in some uncivilised races falls slightly short of the normal; that in other it transcends the normal by a peculiar process of degeneration between the sphenoid and ethmoid, and that increased capacity of the cranial cavity in the progress of civilisation is obtained almost out of those flat surfaces above and below the temporal ridges which give savage Trans., 1870). country during the last twenty-five years, by referring shortly to the homological writings of three eminent anatomists-Professors Owen, Goodsir, and Iuxley.

For the first time in English literature, the great problems of thi description were dealt with in Professor Owen's work already referred to published in 1848 ; and it is unnecessary to say that, notwithstanding the presence of unquestionable errors of theory, that work was a most valuable and important contribution to science. The faults in its general scope were justly and quietly corrected by Goodsir at the meeting of this Association in I856 in three papers, one of them highly elaborate; and in these he showed that the morphology of vertebrate animals could not be correctly studied while reference was made ex clusively to the skeleton. He showed the necessity of attending to all the evidence in trying to exhibit the underlying laws of structure, and especially of having constant regard to the teachings of embryology. Among the matters of detail which he set right, it may be mentioned that he exposed the untenability of Professor Owen's theory of the connection of the shoulder-girdle with the occipital bone, and pointed out that the limbs were not appendages of single segments correspond ing with individual vertebra. Referring to the development of the hand and foot, he showed the importance of observing the plane in which they first appear, and that the thumb and great toe are originally turned toward the head, the little finger and little toe toward the caudal end of the vertebral column. But he probably went too far in trying to make out an exact correspondence of individual digits with individual vertebral segments, failing to appreciate that the segmentation originally so distinct in the primordial vertebræ becomes altered as the surface of the body is approached: a truth illustrated in the vertebral columns of the plagiostomatous fishes, in the muscle-segments over the head in the pleuronectids, and in the interspinal bones bearing the dorsal and anal fin-rays of numbers of fishes, but so far, as I know, not hitherto sufficiently appreciated by any anatomist.

Goodsir also exploded, one would have thought for ever, the erroneous theory of the correspondence of the mammalian tympanic plate with the quadrate bone of birds and the suspensorium of fishes, directing attention to the neglected but just appreciation by St. Hilaire of the homological importance of the ossicles of the ear, and to the embryological work of Meckel and Reichert. But undoubtedly he fell into great mistakes of his own in matters of detail connected with the exceedingly difficult question of the correspondence of the bones of the skull, the principal of these probably being an unfortunate notion that the great frontal of fishes was a bone which disappeared from the skull. of mammals, a notion which spread its influence over his determination of a number of other elements, and introduced a confusion which made his paper on the skull hard to understand.

In 1858 , Professor Huxley delivered his Croonian Lecture on the Vertebrate Skull ; and in I863, his lectures at the Royal College of Surgeons on the same subject. He profited by the wisdom of Goodsir, and studied the works of Rathke, Reichert, and other embryologists. But, rightly or wrongly, he took a step further than Goodsir. He as. sumed from the first that the homologies of adult structures could be determined by development, and that by that study alone could they be finally demonstrated. As regards the skull, the constitution of which always remains the central study of the vertebrate skeleton, his writings marked the introduction of a period of revulsion against not only the systems of serial homologies previously suggested, but even against any attempt by the study of the varieties of adult forms to set them right. Mr. Huxley has added materially to the previously existing number of interpretations as to what elements correspond in different animals and, in doing so, has found it necessary to make various additions to the already troubled nomenclature. Those who consider these changes correct will, of course, see in them a prospect of simplicity to future students ; but to those who, like myself, have never been able to agree with them, they are naturally a source of sorrow. Among the changes referred to, may be mentioned the theory of the "periotic bones". That theory I venture to think a very unfortunate one, introducing a derangement of relations as wide-spread as did Goodsir's theory of the fronta bone. And do not think me presumptuous in saying so, seeing that this theory is in antagonism with the identifications of every anatomist preceding its distinguished originator, not excepting Cuvier and Owen; nor is it easy to discover what evidence it has to support it against the previously received decision of Cuvier as to the external occipital and mastoid of fishes. Without entering into the full evidence of the sub. ject, it may be stated that, so far as this theory affects the alisphenoid in the skull of the fish, it must be given up, and the determination of Professor Owen must be reverted to, when it is considered that in the carp the third and fourth nerves pierce what that anatomist terms the orbitosphenoid, the bone which is alisphenoid according to the theory which terms the alisphenoid of Owen the prootic. A proof still more 
striking is furnished by Malapterurus and other Silurids, in which the bone in question is pierced by the optic nerve. That being the case, the prootic theory will be seen to have arisen partly from giving too much importance to centres of ossification, and partly from considering the nerve-passage in front of the main bar of the alisphenoid of Owen as corresponding with the foramen ovale of man rather than with the foramen rotundum and sphenoidal fissure. A spiculum, however, separating the second from the third division of the fifth nerve, and having therefore the precise relations of the mammalian alisphenoid, does exist in the carp and other fishes. But in reptiles Professor Huxley's determination of the alisphenoid is right, and Professor Owen's clearly wrong ; for in the crocodile the alisphenoid of Huxley and others is perforated by the sixth nerve, so that it cannot have any claim to be called orbitosphenoid. I must, however, maintain against Professor Huxley's view of Professor Owen's determination of the nasal in fishes, notwithstanding that Professor Owen has failed to appreciate the exact relation of that bone to the nasals of mammals, and has thereby laid his position open to attack. The arguments on that point Professor Huxley was good enough to lay before the public fourteen years ago, by kindly reading for me before the Royal Society a paper, which subsequently appeared in its Transactions; and I am not aware that anyone has since attempted to controvert them.

I shall not trouble you further with such matters of detail; but it will be clear from what has been said that the beginner in comparative anatomy must at the present day find himself at the outset, in the most important part of his osteological studies, faced with a diversity of opinion and confusion of nomenclature sufficient to produce much difficulty and to have a repelling effect on many minds. Such difficulties might well be encountered with enthusiasm where a belief existed that behind them lay a scheme of order and beauty; but not many will spend time investigating such intricate details if they doubt the interest of the general conclusions likely to be reached by mastering them. On this account, it is a great pity that the scepticism generated partly by the difficulties of the subject, and partly by reaction from the dogmatism of the admirers of Oken, does too frequently discourage the investigation of the serial homologies of the parts entering into the segments of the skull, and the determination of the nature and number of those segments. It is a pity that so much clamour has been made for a number of years against the expression "vertebral theory of the skull", because fighting against words is but stupid warfare at the best, and because all that was really meant, and that could be justly stated, could have been brought into prominence without objecting to a timehonoured phrase. It is questionable if anyone who ever used the convenient term "vertebral theory" meant to indicate more than a certain community of plan on which were built the segments of the skull as well as those of the spinal column; that, in fact, the two constituted one complete chain, of which the first few segments were so different from the rest that, till Oken pointed the fact out, it was not recognised that they were segments lying in lineal continuity with the rest. But the matter has recently stood thus : that to some minds, in the imperfect state of our knowledge, one thing seemed essential to a segment comparable with the rest, and to others something else seemed requisite ; and the oddity of the position of affairs is this, that the objectors to the phrase "vertebral theory" have been as crotchety in setting up imaginary essentials to a segment as their neighbours. On the one side, we were taught to expect certain definite osseous elements in each segment, to which definite names were given; while, on the other, in opposition schemes, centres of ossification have been built on as matters of primary consequence, although a glance at the modifications in the vertebral column proper might convince anyone that they are things of the very slightest importance morphologically. Also those who have objected to speaking of cranial vertebræ, have put great importance on the point at which the chorda dorsalis terminates, although it has been long known that in one animal the chorda dorsalis runs right on to the front, that in others it fails to enter the skull at all, while in the majority it passes for a certain distance into the base. Johannes Müller, on such grounds, concluded, thirty years ago, that the presence of chorda dorsalis was not necessary to constitute a cranial vertebra ; and there seems no reason to doubt that he was right. Looking at the early embryo, the cerebro-spinal axis is seen to be one continuous structure and the walls of the canal containing it are likewise manifestly continuous, not at first distinguishable into a spinal and a cranial portion. Looking at the adult condition, in the higher classes the vertebra of the tail are seen dwindling into mere bodies developed round the chorda dorsalis, and giving off rudimentary processes without separate centres of ossification, while towards the head the bodies diminish and the arches enlarge ; and in the skull the chorda, round which the bodies in the rest of the column are developed, comes to an end, and the neural arches are enormously enlarged and have additional centres of ossifica- tion, precisely as in the mammalian thorax costal centres of ossification are found which do not exist in the costal elements of cervical vertebræ. It would, therefore, be quite as justifiable to object to the term vertebra as applied to a joint of the tail because it has no lamina, on none with separate centres of ossification, as to object to its applicability to segments of the skull because the chorda is absent, or the osseous elements different in number from those found ustally in tho segments of the trunk.

However, it is gratifying to observe that, among the most recent additions to morphological anatomy, there is a highly suggestive papen by Professor Huxley, appearing in the Royal Society's Procedtings frit December last, and entitled "Preliminary Notes upon the Brain ancl Skull of Amphioxus lanceolatus", in which the learned professor, who has for many years been the most determined opponent to the mention of cranial vertebræ, declares, so far as I can comprehend his meanin'r, that the region of the head represents no less than fourteen segments, all of which he terms protovertebre Amphioxus. This determination of correspondence is made the more remarkable by being followed r.p with a suggestion that the numerous protovertebrx lying in front of the fourteenth in Amphioxus are represented only by muscles and nerves in the higher vertebrates.

I hail this paper as being practically at last an ample acknowleds; ment that there is no escape from admitting the correspondence of tine region of the head with the segments of the trunk; but the details of the new theory scarcely seem convincing; and I might have preferrel to leave its discussion to others, were it not that the notions which it opens up are far too important to allow it to be passed over in any account of the present state of opinion on the subject of vertebrnte morphology. The argument in this new theory runs thus: that the palate-curtain of Amphioxus is homologous with that of the lamprey, and that the palate-curtain of the lamprey is attached below the ear; that, therefore, all the seven segments seen in front of the palatecurtain of Amphioxus are represented by parts in front of the ear in the lamprey and the other Vertebrata. Again, the branchial arches of the higher Vertebrata are assumed to be of the nature of ribs; and in none of the Vertebrata next above Amphioxus " are there more than seven pairs of branchial arches; so that not more than eight myotomes (and consequently protovertebræ) of Aikphioxus, in addition to those already mentioned, can be reckoned as the equivalents of the parachordal region of the skull in the higher vertebrates". Everything, observe, depends on the segment to which the palate curtain of Amphioxus belongs. Now, I have alrearly pointed out to you that the segmentation of the vertebrate body is not perfect; and there is no method by which the alimentary canal, of which the mouth and palate are the first part, can be divided into segments corresponding with the cerebro-spinal nerves. Most certainly we cannot judge that a portion of a viscus belongs to a particular segment from its lying underneath some other structure in definite relation, like the ear, to the cerebro-spinal system: for then should we be obliged to grant that one-half or more of the heart belongs to segments in front of the ear, since it is undoubtedly so situated in a chick of the thirty-sixth hour. But the brachial arches are in front of the heart, and, according to the theory which we arc considering, are behind the ear; thus the principle assumed in the starting-point of the theory is taken away.

Again, it is important to observe that the branchial skeletal arches cannot be ribs, for they lie internal to the primary circles of the vascular system formed by the branchial arteries and veins, while the ribs are superficial to both heart and aorta. If the ribs are represented at all in the branchial apparatus (and I doubt it very much), it is by the cartilages superficial to the gills in sharks, rays, and dog fishes; and it would seem impossible for any one who has dissected them to loubt that those cartilages are homologous with the branchial skeleton of the lamprey, which they somewhat resemble. In fact, if the external and internal branchial openings of the lamprey be enlarged, its gills are rcduced to a form similar to those of the shark.

There is nothing in this, however, which interferes seriously with the proposed theory of the skull. It is merely a point in the argument which I have thought right to clear. More important it is to remark that, on the supposition that numerous protovertebræ are represented in the region of the head, there are most serious difficulties interfering with the idea that they are, as Professor Huxley states, represented only by muscles and nerves in the higher Vertebrata; and that there is any correspondence between "the oculo-motor, pathetic, trigeminal, and abducens nerves with the muscles of the eye and jaws", and the regular nerves and muscle-segments of the fore part of Amphioxus. Even in the lamprey, the eyeballs are supplied with muscles similar to those to which, in other vertebrates, the oculo-motor, pathetic, and abducens are distributed; and I find in the large species that, notwithstancling this, the series of regular muscle-segments is continued over the head- 
not, indeed, in the same way as in Mixine, but in a highly instructive and curious manner. The five foremost muscle-segments have their upper extremities attached considerably in front of the nasal opening by a shcrt tendon, which touches its fellow in the middle line; and, extending thence in an outward and backward direction, they pass behind the eyeballs, the first two running in front of the first gillpouch, and the third lying over it. Therefore, in this instance, as surely as the nostril is in front of the cye, so surely the upper extremities of these muscle-segments are shifted forwards out of their morphological place, probably in connection with the great protrusion of the jaws for the physiological purpose of forming a sucker. There is no cscape from granting this shifting, even were it possible to believe that the eycball could be further forward than the nostril; for, while the fifth muscle-segment can be traced in front of the nostril, the sixth occupies the interspace between the skull and first vertebra, so that, if the muscle-segments are taken as a guide, the whole skull, forward to the nostril, belongs to one intersegmental space: a view which is clearly absurd. The succeeding intermuscular septa correspond each with a cartilaginous vertebral arch; and it is interesting to observe that the branchial cartilages are not placed one for each septum, like the fibrous representatives of ribs detectable within the septa; for the second cartilage is opposite the sixth septum, the third opposite the ninth, the fourth opposite the eleventh, the fifth opposite the thirteenth, and the sixth and seventh opposite the fourteenth and fifteenth septa; and this is one reason for doubting that even these superficial branchial cartilages, though attached to the vertebral column, are to be regarded as ribs.

It may be noticed as a wholesome symptom in anatomical speculation, that the new theory which has led to these remarks is founded on arguments drawn altogether from comparison of different species, and not from embryology : a very remarkable circumstance, as coming from one who so lately as last autumn reiterated in this Section his slowness to believe in reasonings founded on adult forms, and even on "later development". The wisest know so little, that humanity must be content to gather information from every possible source, and leave no set of ascertained facts out of view in attempting to arrive at generalisations. If we had before us all the adult anatomy of every species that ever lived on the earth, we should only then have the record completed from which to frame a full system of morphology; and, as matters stand, we must translate embryological phenomena with the aid of the series of alult forms, as well as translate the teachings of the atult series with the aid of embryology.

Falling back on my proposition, that the segments of the vertebrate body are nowhere complete, and that segmentation at one depth may exist to a greater extent than at another, I may mention certain eml:ryological phenomena in the brain which have received too little attention, and which to some extent warrant belief in a larger number of segments in the head than is usually admitted; although I do not see that they are necessarily at variance with that theory of seven segments in every ossified skull which I indicated in 1862 . In the chick, in the middle of the second day of hatching, already is the third cerebial vesicle clivided into a series of five parts, separated by slight constrictions, the first part larger than those which succeed, and the last part narrowing to the spinal cord. The auditory vesicle lies opposite the constriction between the fourth and fifth parts. At the end of the second day and during the third, these divisions assume dimensions which give them a general appearance exceedingly similar in profile to the protovertebrae of the neck. In the following day they exhibit a more complex appearance, and after that the first compartment alone remains distinct as cerebellum, while the divisions between the others disappear in the thickening of the cerebral walls. In their first two tages, Mr. IIuxley, whom I have already referred to so often, has figured these crenations, but he has not, so far as I know, described them.

I may also direct attention to another embryological point, to which I referred last year at Belfast as a probability. I speak now from observation. That which is termed the first cerebral vesicle in the early part of the second day of hatching of the chick, is an undifferentiated region of the brain from which a number of parts emerge successively from behind forwards. As early as the thirty-sixth hour the optic nerves can be traced, separated from the rest of the vesicle by distinct elevations of the floor of the brain, reaching inwards to the constriction between the first and second vesicles : and as early as this date the first trace of bifidity of the brain in front may be discerned-that bifidity which, to my thinking, is only one of several instances of longitudinal fission in the fore part of the head, the trabecula presenting another instance of the same thing, and the cleft between the maxillary lube and the part of the head above it a third; while in the muscular system such longitudinal cleavage or fission is common even in the trunk. In a chick of the third or fourth day, when rendered very transparent, the optic nerves can be seen extending from beneath the front of the optic lobes; while in front of the optic lobes there are placed in series from behind forwards a posterior division of the first vesicle, an anterior division, the cerebral hemispheres, and the olfactory lobes. Thus there is a large supply of material presented in the brain for the study of segmentation: the difficulty to be overcome by future inquiry and careful collation of all available facts is to determine the value of the parts placed one in front of another.

Perhaps I have occupied time too long with matters involving a large amount of technical detail ; but I trust that I may have, in some measure, illustrated that both in aim and in accomplished work anatomy is no mere collection of disconnected facts, no mere handmaid of the physician and surgeon, nor even of physiology. I do not doubt that it is yet destined, as dealing with the most complex sequences of phenomena, to take the highest place among the sciences as a guide to philosophy. One cannot help noticing the increased importance now given to natural history studies as a part of education ; and it is worth while to note that it is most of all in anatomy and physiology that the close connections of matter with mind are brought under review - physiology exhibiting the relations of our own mental being to our bodies, and anatomy revealing a body of organised nature, whose organisation points to a source of beauty and order beyond.

The people of Bristol do well to rally round their medical school. They do well to furnish it with buildings suitable for the prosecution of all the natural history studies which adhere to medical education ; and they do well to join with that school a complete college of literature and science. Let us hope that they will make it worthy of so wealthy and historic a city. But if they will have their medical school the success which in so flourishing a locality public enthusiosm may well make it, and if they will have it aid as well as be aided by a school of general education, let them follow the system latterly adopted in Oxforc and Cambridge, long carried out in the Universities of Scotland, and recognised, though not in all instances sufficiently provided for, in Ireland. Let anatomy, human and comparative, receive its place as an important and fundamental science. Let thorough and adequate provision be made for its being taught as a science; and see that it do not, as in too many medical schools which shall be nameless, degenerate to the etymological and origiral meaning of the word, a mere cutting up of carcasses.

\section{ON TRACHEOTOMY IN CROUP AND DIPHTHERIA.*}

\section{By GEORGE BUCHANAN, M.A., M.D.,} Professor of Clinical Surgery in the University of Glasgow.

Tine prevalence and fatality of diphtheria of late years, as may be seen by a perusal of the Registrar-General's returns, has drawn the attention of the profession to the etiology of that disease, and has recently given rise to a controversy as to the identity or non-identity of croup and diphtheria. Many able papers have appeared in the pages of the BRITISII MEDICAL and other journals on this subject, and to them I refer those interested in the question; but there is one point of resemblance which is of the utmost importance in a practical point of view. Although the two diseases may be as distinct as to cause, course, and sequela, as scarlet fever is from simple tonsillitis, yet both are characterised by the effusion, on the mucous membrane of the air-passages, of a tough false membrane. This membrane may differ in its nature and in situation, at least at the commencement, but the tendency in both cases is to obstruct the breathing and cause suffocation.

This seems so self-evident that I must almost apologise for mentioning it; but $I$ have been so often met with the objection that, because the primary disease causing the effusion is diphtheria and not croup, therefore it is hopeless to interfere, as the operation will not cure the specific disease, that I have considered it not out of place to introduce it. We might as well refuse to open an abscess of the tonsil which was about to choke a patient suffering from scarlatina, because the operation will not cure the fever, as refuse to relieve a patient from instant death from suffocation because the operation is not a cure for diphtheria.

Now, the point I wish to bring out is, that there is a stage both in croup and in diphtheria at which it becomes evident that recovery is hopeless and death from suffocation certain. It is quite true that it is exceedingly difficult to say when that stage has arrived, and mistakes may sometimes occur; but I believe practically it is better to err on the safe side, and acknowledge the inefficacy of treatment, rather than delay till it is too late to resort to the last resource. Tracheotomy pir se, though

* Read before the Surgical Section at the Annual Meeting of the British Medical Association in Edinburgh, August 1875 . 